\title{
El "individualismo metodológico" de Max Weber y las modernas teorías de la elección racional
}

\author{
Luis Armando González
}

\section{Introducción}

El objelivo de eslas notas es efectuar una somera reflexión en lorno a las consecuencias epistemológicas y ontologicas que se derivan del llamado "individualismo metodológico". En este sentido, partimos de los supuestos siguientes: a) cualquier perspectiva melodológica se funda en unas premisas epistemológicas subyacentes, que a su vez son alimentadas por aquel horizonte metodológico; y b) cualquier perspectiva metodológica, además de unas determinadas premisas epistemológicas, supone unas determinadas premisas ontológicas que apuntan a cormo se constituye y cuál es la dinámica de la realidad que interesa al invesligador. En el caso de las ciencias sociales, eslas premisas ontológicas apuntan a cómo se constituye la realidad social y cuál es el papel que los individuos humanos desempenan en la misma.

El "individualismo metodológico", como su nombre to indica, es anle todo un método, es decir, un modo de abordar los problemas sociales que privilegia su "individualidad histórica" (Max Weber). Sin embargo, no es sólo un método. Es también una forma de comprender los alcances y límites del conocimiento cienlífico-social $y$, a la vez, es un modo de entender la constilución de la realidad social. Y cuando nos planteamos preguntas no acerca de cómo se puede conocer, sino sobre qué es lo que se puede o no se puede conocer de ésta y cómo es que está constituida, entonces nos movemos de un ámbilo metodológico a un ámbito no sólo epistemológico, sino también ontológico. 
Y es que entre melodología, epistemología y onlología exisle una unidad indisoluble. Pensar en una lorma de conocer la realidad (mélodo) supone, al mismo tiempo, pensar en los alcances y límites del conocimiento que prelendemos alcanzar (epislemologia) y en cuál es la naluraleza de la realidad objeto de nuestro conocimienlo (ontología). No se trala, por los demás, de una vinculación meramente "externa" entre estas Ires dimensiones del saber, sino de una unidad esencial entre ellos: en la consideración metodológica se hace presente ipso facto la consideración epistemológica y la consideración ontológica. Asimismo, esta regla es válida cuando nuestro punto de partida es no la metodología, sino la epistemologia o la onlologia. Si nos preguntamos por los alcances, los límites y las posibilidades de nuestro conocimiento (epislemologia), nos las tendremos que haber necesariamente con la pregunta acerca de cómo es es que se construye el conocimiento (mélodo) y sobre cuál es la naturaleza de lo conocido (ontología). Si nos preguntamos acerca de cuál es la naturaleza de la realidad (ontologia), inexorablemente tendremos que enirentar el problema de cuál es la mejor manera de conocer esa realidad (método) y qué es lo que puedo o no puedo conocer de ella (epistemología).

Nuestra hipótesis es que en el "individualismo melodológico" no sólo hay una propuesta acerca de cómo se puede conocer la realidad social —normalividad metodológica-, sino una propuesta acerca de qué es lo que se puede conocer de esa realidad —normatividad epistemológicay sobre cuál es la constitución de la misma -normatividad onlológica-. Es decir, hay una propuesta en tomo al modo más adecuado de conocer los hechos sociales, asi como en lorno a los alcances y limiles del conocimienlo sociológico y en torno a la constitución de la sociedad. La propuesta melodológica es, al mismo liempo, una propuesta epislemológica y una propuesta ontológica.

Por consiguiente, para comprender el alcance real de la propuesta melodológica, es pertinente indagar acerca de las propueslas epislemológica y ontológica. $Y$ esto -en el caso concreto que nos interesasólo se puede hacer partiendo de la propuesta melodológica propia del "individualismo melodológico".

A menudo no se cae en la cuenta de la mutua imbricación que existe entre lo metodológico, lo epislemológico y to onlológico. $Y$ ese olvido puede tener graves consecuencias a la hora de adoplar una u olra perspectiva metodológica. Es decir, cuando se asume un método, no sólo se hace una opción meramenle melodológica, sino que se asume también un horizonte teórico -indisoluble de la perspectiva metodológica- que nos dice qué podemos o no podemos conocer de la realidad y cuál es la 
naturaleza de esta realidad. Cuando se adopta un método se adopta al mismo tiempo la leorla del conocimiento y la teoría de la realidad de las que ese mélodo es expresión. Asumir una perspectiva metodologica determinada es asumir la perspectiva epistemológica y ontológica de la cual aquella se nutre.

Nuestro propósito básico consiste en examinar las consecuencias epistemológicas y ontológicas que se derivan del individualismo metodológico" como perspectiva melodológica en Ciencias Sociales. De esta perspectiva melodológica se derivan una serie de consecuencias en torno a las alcances, los limites y las posibilidades del conocimiento sociológico, así como también en torno a la constilución de lo social, que nosolros intentaremos explicitar. En este sentido, expondremos -primero- sus supuestos metodológicos y $\rightarrow$ segundo- reflexionaremos sobre las implicaciones epistemologicas y onlológicas que se derivan de los mismos.

\section{El "indlvidualismo metodológico" clásico}

\subsection{Antecedentes: el debate "explicaclón-comprensión"}

El "individualismo metodológico" se configura -como propuesta melodológica - en el marco del "debate melodológico alemán en torno a la especialidad y autonomia de la ciencia histórico-social (...), al cierre del siglo XIX y comienzos del XX"m. Es decir, se configura en tomo al debate "explicación-comprensión" que ocupó buena parte de las discuciones metodológicas y epistemológicas de finales del siglo XIX y comienzos del XX (J. M. Mardones).

Dilthey, en su Introducción a las ciencias del espiritu, fue uno de los primeros que intentó dotar a las ciencias humanas o sociales -"ciencias del espíritu"- de una aulonomía y especilicidad propias. Sin embargo, su intento se irustró al no lograr satarse del positivismo imperante en las ciencias explicativas, es decir, en las ciencias nalurales (Otlo Apel). Los intentos de dotar a lo humano-social de una especificidad y autonomía propias se continuaron en los trabajos de Husserl, donde aparece el problema del "sentido" como un problema central de la investigación hislórica. Heidegger prolundiza esla línea de investigación al introducir el problema de la "comprensión" — alcanzada por el lenguaje - como algo central para entender la especiticidad de lo humano ${ }^{2}$. La tradición heideggeriana -que privilegia la comprensión como vía de acceso a lo socio-hislórico- fue continuada por la Iradición hermenéutica impulsada por H.G. Gadamer y enriquecida luego por la última generación de la Escuela de Frankfurt. 
Hemos esbozado en sus grandes líneas el desarrollo del "horizonte de la comprensión". Es decir, ese modo de abordar los fenómenos humano-sociales desde una perspectiva distinta a la seguida en el ámbito de las ciencias naturales: el "horizonte de la explicación". No se buscan leyes explicativas -causales-, sino la comprensión del sentido linguísticamente mediado de los tenómenos en su concreción histórica. Dilthey tue el primero que orientó sus esfuerzos en esta dirección; esfuerzos que fueron continuados - como ya dijimos- por Husserl, Heidegger, Gadamer y los teóricos críticos de la última epoca. Esta ha sido, sin embargo, una dirección que podriamos llamar "filosófica" en la apuesta por los inlereses de la comprensión. Hay olra dirección, una dirección que podriamos llamar "científica" en el sentido de que sus prelensiones apuntan hacia la formulación de una melodología especifica de análisis de la realidad social.

Esta segunda dirección -formulada en su versión clásica por Max Weber - se ha prolongado hasta nuestros dias en las diversas teorias de la rational choice y la acción colectiva. Autores como J. Elster, J. Buchanan, M. Taylor, M. Olson, R. Benjamin', se remilen al "individualismo metodológico" de raices weberianas para alcanzar una comprensión de los tenómenos sociales complejos propios de nuestra época.

\subsection{La propuesta del "Indlviduallsmo metodológlco" de Max Weber}

La formulación clásica de esta perspectiva se encuentra en en Max Weber, concretamente en el llamado "individualismo metodológico" que él pretende fundar. La obra de Weber se inserta al inlerior del debale explicación-comprensión y evidentemenle él apuesta por los intereses de la segunda, aunque matizada por la búsqueda de una cierta forma de explicación causal de los tenómenos socio-históricos: en rigor, se trata de una propuesta comprensivo-explicativa.

Asimismo, la propuesta weberiana no posee prelensiones totalizantes y omniabarcadoras. Porque electivamente se puede optar por la comprensión, y hacerlo desde una apuesta por el todo social e hislórico; es decir, desde una apuesta por lo coleclivo. Las elaboraciones de la última generación de la Escuela de Franklurt defienden -desde el horizonte de la comprensión- los fueros de lo colectivo, por sobre los intereses de lo individual. Sin embargo, desde la comprensión se puede aposlar por los intereses de lo individual. Se puede oplar por un "individualismo metodológico", es decir, por una perspectiva metodológica que privilegie en la formación de su andamiaje conceplual la singularidad (individualidad) histórica de los fenómenos, partiendo de la individualidad de la acción racional humana. Esta es la apuesla de Weber. Esle es 
el punto de partida de su "sociologla comprensiva".

"La mela de la comprensión -escribe Weber- es también, en definitiva, la razón por la cual la sociología comprensiva trata al individuo singular y a su actuar como la unidad última, como un 'átomo', si se nos admite la peligrosa comparación‘... La "acción, en cuanto orientación imtencional de la propia conducta, comprensible en su sentido, sólo existe para nosotros como conducta de una o varias personas individuales"s.

Por tamo, la acción individual ocupa un lugar central en la sociologla weberiana. "Si comprensibilidad y explicalividad son exigencias metodológicas, sólo la acción individual es 'comprensible"s. Se trala entonces de alcanzar una lommulación conceptual rigurosa y científicamente pertinenle de la acción individual. Para Weber, la formación de conceptos es una conditio sine qua non para la elaboración de un saber con pretensiones de cientificidad. La ciencia hislórica de su tiempo está en bancarrota - nos dice Weber- justamente "por la ambiguedad y equivocidad de sus conceptos y enunciados, razón por la cual la lógica (la gramática conceptual) más que la verificación-falsación empírica es el árbilro decisivo y urgente del desarrollo de la ciencia histórica"7.

El "individualismo metodológico" cumple con el requisito fundamental de rigor conceplual en sus formulaciones teóricas, comenzando por su conceptualización de "acción individual".

'El 'individualismo metodológico' consiste en formular un conceplo de acción individual estrictamente racional que satisface los 'requisilos lógicos' de no contradicción-Lnivocidad-evidencia racional y 'los requisilos melodológicos' de comprensibilidad y explicalividad, por cuanto puede ser incorporado como sujeto de un enunciado causal y como sujeto del que se comprende la razón o el motivo de su acción o causación"s.

Es por eslo que se puede hablar en Weber de un "racionalismo melodológico" (Aguilar Villanueva):

"El llamado 'racionalismo metodológico' de Weber descansa en su convicción de que para el logro de los fines cognoscitivos de una ciencia histórico social ('comprensivo-explicaliva'), el medio adecuado y productivo es la construcción de conceptos que analicen y representen los llamados hechos históricos o hechos sociales como 'actuares racionales respecto de fines'. La traducción conceptual de los hechos empiricos en actuares racionales será la regla del método"s. 
Weber tiene una noción muy especifica de lo que es la racionalidad, es decir, una noción que arranca básicamente del ámbito económico.

"Es la racionalidad formal-instrumental-respecto de fines que ve en la obra de la economia capitalista, en el estado constitucional, en la administración pública, en las organizaciones sociales, en la ética profesional y crecientemente en el ámbito de las decisiones privadas $^{\text {110. }}$.

Por otra parte, para Weber el concepto de "acción individual" es un "concepto limite"; una "categorla", al modo kantiano, que permite ordenar las representaciones $\theta$ intuiciones de la experiencia (Aguilar Villanueva). El concepto de "acción individual" cumple la lunción ser un medio heurístico, "porque en él no se llegaba al conceplo histórico, pero sl, a través de él, se alcanzaba el conceplo histórico, el conceplo de la acción efectivamente sucedida $y$, por ende, el enunciado causal electivo"". El concepto de "acción individual" es un "tipo ideal" o "lipo puro" (Aguilar Villanueva).

Pero, como sehala Aguilar Villanueva, soslener que el conceplo de "acción individual" es lundamental para comprender-explicar los sucesos históricos y sociales no implica afirmar que los individuos son la causa de dichos sucesos.

"De ello no se sigue el enlendimiento del individualismo melodológico como equivalente a un supuesto teórico particular histórico que afirma como única y predominante la causalidad de la acción individual en una clase de sucesos o en una época determinada. Eslo es ya enirar en el terreno de la formación de hipólesis y de sus procedimientos de prueba. Weber prelende decir únicamenle que no se pueden tormar los conceptos de los términos de cualquier enunciado causal hislórico posible más que construyéndolos como acciones individuales 0 a partir de acciones individuales"'12.

El corpus teórico de la "sociologia comprensiva" se edifica a partir del conceplo de acción individual.

"Sólo los conceptos construidos como acciones individuales o a partir de ellas hacen posible llegar a conceplos hislóricos que cumplan el requisito lógico de no contradicción y univocidad en su deteminación. En suma el llamado individualismo melodológico (en Weber) pretende cumplir tareas lógicas de conceplualización de términos, más que tareas de invención y prueba de hipótesis. Es anle todo una heurística del concepto más que una heuristica de la hipótesis"13.

En resumen, siguiendo a Aguilar Villanueva, podemos decir que el "individualismo metodológico" de Max Weber fue: primero, "una propues- 
ta polémica contra los 'conceptos colectivos"'; segundo, "una propuesta relacionada con el requisito melodológico de la 'comprensión' de los hechos sucedidos"; lercero, "una propuesta de construcción de los conceplos como acciones de individuos... $\infty$ mo acciones-relaciones sociales de individuos"; cuarto, "una propuesla que distinguó entre la posición valorativa del 'individualismo' y la posición lógica de la conceptualización en clave de acciones individuales; quinto, "una propuesta que no incluyó el supuesto de que lodos los sucesos, sin excepcion, hayan de ser explicados como consecuencias de la acción de un individuo (el héroe), de unos individuos (élite) o de todos los individuos (masas)" ${ }^{\prime \prime}$.

\subsection{El "individuallsmo metodológlco" contemporáneo}

"Las ciencias sociales están hoy bloqueadas por una ofensiva como no se habia vislo desde la década de 1980: una tendencia deliberada a imponer el monopolio del método económico a todos los estudios de la sociedad"15.

Así diagnostica Adam Przeworski la siluación de las ciencias sociales contemporáneas. En electo, en la actualidad se ha extendido en el pensamienlo cienlífico social la pretensión que Schumpeter formuló en su momento de examinar la política según las reglas del mercado". Hoy considerar la política como intercambio es algo casi ineludible si se quiere hacer ciencia política. Como dice Buchanan:

"No hay fronteras que puedan trazarse entre la 'economia' y la 'politica' o entre 'mercado' y 'gobierno', y tampoco entre el 'sector privado' y el 'sector público'... Los economislas pueden conlemplar la política, y el proceso político, en lérminos del paradigma del inlercambio"17.

Y esto vale también para otras esieras de la ciencia social. Hay que estudiar lo social según las reglas de la economia; más aún, hay que esludiar el comportamiento social como un comportamiento económico. El homo sociologicus y el homo politicus no se diferencian en lo absoluto del homo economicus (J. Molinet). Este es el axioma que se ha impueslo en el pensamienlo sociológico contemporáneo. "Los individuos aclúan sobre la base de sus deseos y creencias... La elección política. racional puede representarse en lérminos de los deseos, creencias y pruebas de un actor supraindividual, la 'sociedad'mi.

Desde el mercado ha lanzado un desafío metodológico de carácter individualista a las ciencias sociales (A. Przeworski).

"Tal desatío consistiria en la necesidad de aportar los microtundamentos de los fenómenos sociales que se prelende explicar 0 , dicho de otra forma, en "basar todas las teorias de la sociedad en las 
acciones racionales de los individuos orientadas hacia un fin'"'?.

A esto apunta R. Benjamin cuando escribe:

"Deseo examinar la utilidad del trabajo con el supuesto melodológico del hombre como ser de elección racional. A partir de esla sola suposición inlentaré generalizar de individuos a grupos de elección colectiva (incluyendo insliluciones sociales, económicas y políticas) para poder analizar los problemas asociados con el diseńo de un gobierno en sociedades postindustriales"20.

Hay un relorno hacia el individualismo metodológico de Max Weber, después de un largo período de dominancia de las perspelivas metodológicas holistas o totalizantes que dominaron el quehacer cientificosocial desde principios de siglo hasta los años 70 . Sólo que este retorno se hace desde la economía, con lo que se "ha abierto una profunda brecha en las aproximaciones tradicionales a los problemas de la sociedad'21.

"La ofensiva economicista parece que ha tenido un éxilo nolable, y hoy se 'impone' en las ciencias sociales... la perspectiva de la elección racional (es decir, el supueslo de que las acciones individuales son racionales en sentido instrumental y que a partir de las mismas se pueden explicar todos los fenómenos sociales)"ze.

Una lectura crílica de este proceso nos diría que la "racionalidad instrumental" ha terminado "colonizando" esleras de la realidad social que tendrian que estar regidas por una lógica distinta, como lo es la racionalidad consensual y comunicaliva (J. Habermas, K.O. Apel), es decir, las dimensiones de la acción social "en cuyo seno se configuran las convicciones morales y las orientaciones normalivas"23. La "colonización" de lo cultural, lo social y lo polílico por una racionalidad nacida del ámbito tecno-económico es ahora más fuerte que nunca. La perspectiva de la elección racional (en el sentido descrito arriba) es una expresión más que evidente de la colonización del saber sociológico $-y$ de la realidad que este saber explica- por parte del saber lecno-económico -y de la realidad de la que es función este saber-. Es decir, las ciencias sociales se problemalizan teóricamente desde la lógica de la economia porque en las sociedades postindustriales ( $R$. Benjamin, $D$. Bell...) la racionalidad del mercado ha invadido -ha "colonizado" (Habermas)-las demás esferas de la realidad social.

El comportamiento social y colectivo de los individuos es central en las nuevas perspectivas sociológicas ${ }^{24}$. Esle comportamiento se explica usando los supuestos melodológicos de la economia, es decir, apelando a los agenles individuales como sujetos maximizadores de sus benefi- 
cios y minimizadores de sus costos. Los agentes individuales son por definición egoistas y racionales. Pues bien, si los agentes individuales son esencialmente egoistas y su objelivo básico consiste en maximizar sus beneficios individuales al menor costo posible, ¿como es posible la organización de acciones coleclivas? ¿Qué laclores, además de la racionalidad maximizadora, intervienen en "la lógica de la acción colectiva"? ¿Cuál es "la lógica de la cooperación"? ¿Cómo se vinculan los "intereses individuales y la acción colectiva"? ¿Cómo se relacionan "la racionalidad, la moralidad y la acción colectiva"?25.

La teoría de los juegos ha representado un nolable impulso en el esludio de eslas interrogantes en las que se encuentra involucrada la "lógica de la acción colectiva".

"La teoría de los juegos desenirana la lógica de la acción colecliva, la lógica de la cooperación, poniendo en evidencia cómo los intereses (las preferencias) de los individuos, en su inleracción estratégica, influyen a la hora de decidir si se toma parte o no en acciones colecti-

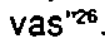

Estas son las preocupaciones centrales que alraviezan las rellexiones de los teóricos de la elección racional (rational choice). El punto de partida metodológico que asumen es el individuo como un ser egoisla y racional. Para explicar los complejos problemas sociales presentes en las sociedades contemporáneas —organización política, comporlamiento electoral, movimientos sociales, elc.- hay que partir de las acciones individuales, que son en esencia "acciones racionales orientadas hacia un lin" (Przeworski). Es decir, hay que asumir incondicionalmente una postura "individualista metodológica".

Para linalizar con este aparlado, veamos cómo J. Elster resume las tesis básicas de la teoria de la elección racional:

"Que el comporlamiento humano puede ser explicado en lérminos de elección racional se está conviertiendo en una opinión general, quizás incluso dominante, en las ciencias sociales... La leoría de la elección racional supone que la gente elegirá el curso de acción prelerido - que considera mejor. Acluar racionalmenle es elegir la mejor acción del conjunto laclible... La persona elegirá la acción que piensa mejor se adapla a sus propósilos, lo que no quiere decir que sea la mejor en un sentido más objetivo. La explicación de la elección racional incorpora y reivindica la relación entre acción, motivos y creencias..."27.

Y sobre el "individualismo metodológico" escribe: 
"Para el individualismo metodológico todas las instituciones, paulas de comportamiento y procesos sociales pueden ser explicados, en principio, en términos de individuos únicamente: de sus acciones propiedades y relaciones. Es una forma de reduccionismo, to que signilica que nos obliga a explicar fenómenos complejos en términos de sus componentes más simples. El reduccionismo es una estrategia central de la ciencia... La 'búsqueda de microfundamentos' —otro término para el individualismo melodológico - ha rendido ya resultados importantes. Una reducción completa, en principio, es posible y se encuentra bastante avanzada una reducción parcial ${ }^{\text {r2e }}$.

\section{Impllcaclones eplstemológlcas y ontológlcas del "Indlviduallsmo metodologlco"}

Como ya dijimos, toda perspectiva metodológica supone unas determinadas premisas epistemológicas y ontológicas determinadas. Esle se el caso del "individualismo metodológico". En lo que sigue, intentaremos poner en evidencia esas premisas, pero lo haremos a la luz del coniraste entre los planteamientos del "individualismo metodológico" y los planteamientos de las tradiciones sistémicas.

\subsection{Supuestos ontológlcos y eplstemológlcos de las tradiciones sistémlcas}

El "individualismo metodológico" nace -y se desarrolla - en oposición a las tradiciones cientifico-sociales que buscan una comprensión holística (o sistémica) de la realidad social. Estas Iradiciones comparten como supuesto epistemológico fundamental la tesis de que las posibilidades del conocimiento de la sociedad como un lodo no liene límites. Las tradiciones sociológicas que se remonlan al maxismo o a la tradición parsoniana comparten esle oplimismo epislemologico fundamental. Ultimamente Niklas Luhmann ha salido en defensa de una visión sistémica de la realidad social, con su teoria general de sistemas".

Asimismo, el supuesto epistemológico asumido por estas Iradiciones se corresponde con un supuesto ontológico que apunta al carácter sistémico o estructural de la realidad social. La realidad social es de naturaleza estruclural (sistémica) y, en consecuencia, es algo más que la sumatoria de los individuos que la constituyen. Más aún, los individuos se constiluyen en cuanto tales por los nexos sociales que los vinculan entre sí. En la formulación clásica de Marx, los individuos "son el conjunto de sus relaciones sociales". Las versiones extremas de esla tradición -que postulan la "muerte del sujeto" y su "sujeción por las estructuras" (Althusser) $)^{30}$ o que postulan una "sociedad sin hombres" (Izuzquiza), es 
decir, una sociedad como "un sislema autorrelerente que crea sus propias condiciones de existencia y sus propias condiciones de cambio"31 al margen y con independencia de los sujelos humanos individuales- llegan hasta nuestros dias, especialmente en las corrienles postestructuralistas neoalthusserianas o en la corrientes sistémicas luhmannianas.

Ontológicamente, en las teorias sistémicas to sustantivo es el lodo social. Los individuos son, en definitiva, una abstracción si se los considera aisladamente, es decir, como sujetos solipsistas, al margen de sus relaciones sociales. Epislemológicamente, en estas leorias sl es posible alcanzar una comprensión global de la sociedad y, por tanto, una comprensión de la función que los individuos desempekan en la misma. Melodológicamente, estas teorías privilegian la elaboración de categorías concepluales de indole macrosocial, es decir, conceplos que apuntan a la caracterización-comprensión de tenómenos colectivos y, a partir de ellos, a la caracterización-comprensión de fenómenos individuales.

Por lo demás, las leorías sistémicas de la realidad social se pueden agrupar en dos grandes tradiciones: a una tradición que podriamos llamar "naluralista" que se remonlaría hasta el mecanicismo y el cientificismo de los siglos XVIII y XIX y que llega hasta nueslros dias en la versión de la teoría de sistemas de Luhmann en la que, en el londo, la sociedad es visla como un sislema cibernético; y b) una tradición hermenéutica que se remontaria a $W$. Dilthey y que, pasando por la obra de H. G. Gadamer, llegaria hasta nuestros dias con los aportes de la teoría critica de la Escuela de Frankfurt y en la que la sociedad es vista como un sistema de relaciones intersubjetivas.

Por otra parte, incluso en el propio Max Weber no es dificil encontrar una prelensión de globalidad en la explicación de los fenómenos sociohislóricos. Es decir, si bien Weber parte de la acción racional individual, su sociologia comprensiva apunta a dar cuenta de la dinámica global de la sociedad moderna. Cuando Weber - como bien ha sefialado Habermas- examina la "autonomización de las esferas de valor" a que conduce el proceso de racionalización de Occidente, lo que hace es ofrecer una visión sistémica - y dinámica - de la sociedad capitalista de su tiempo. Sólo que en él se trala de un sistema que tiende -por la lógica de la racionalización- hacia la Iragmenlación.

Los sistemas sociales modernos se iragmentan y el saber sociológico tiene que hacerse cargo de esa iragmentación. El esfuerzo teórico de Weber consisle justamente en dar cuenta de la dinámica que subyace a la "aulonomización de las esferas de valor" que viven las sociedades modernas. Su punto de partida melodológico para enfrentar este reto leórico es la acción individual con arreglo a fines. Por tanto, en Weber 
también se hace presente un cierto optimismo epislemologico respecto de las posibilidades que tiene el hombre de conocer la sociedad como un todo. Hasta se podria decir que su obra es una espectacular muestra de esie oplimismo. Pero lambién se podrla decir que el entusiasmo de Weber por alcanzar un comprensión global de la sociedad se ve constrefiido en la medida en que sus estudios sobre los procesos históricosociales le hacen caer en la cuenta de que las sociedades occidentales se encaminan hacia la desestructuración de sus ámbitos fundamentales, más que hacia la conformación de un todo sistémico.

Por lanto, en Weber, no se puede alcanzar una comprensión de la sociedad global por la fragmentación generada por los procesos de racionalización. Y esto justamente apunta a una tesis onlológica fundamental en el pensamlento weberiano: la sociedad modema está en una dinámica de desestructuración debido al avance de los procesos de racionalización que conducen a la aulonomización de las esferas de valor. Enlonces, para este aulor, no hay una visión sistémica de la realidad social porque ésla se le revela como tragmentada. $Y$, en ese sentido, el conocimiento que se puede construir de esa realidad no puede menos que hacerse cargo de los límiles que la propia dinámica sociohislórica le impone. No es posible alcanzar un conocimiento del todo social porque ese todo social se Iragmenla en sus ámbilos lundamentales, es decir, en sus ámbitos tecnoeconómico, político y cullural. De aqui que tenga que acudirse a una perspectiva metodológica que permita salvar las dificultades que impone a un conocimiento sociológico con prelensiones de globalidad la tragmentación de la realidad social. Esta perspecliva metodológica, para Weber, tiene que fundarse en la noción de acción racional-individual.

En resumen, en Weber encontranios: a) una realidad social tragmenlada (problema ontológico); b) la imposibilidad de lograr una comprensión de la sociedad global (problema epislemológico); y $c$ ) la necesidad de abordar la realidad social a partir de la categoría de acción individual (problema melodológico). La realidad social sólo se puede conocer parcialmenle y ello supone considerar los lenómenos sociales como hechos individuales. El concepto de acción individual es un instrumento analílico que contribuye a alcanzar una comprensión de los hechos sociales en su singularidad histórica.

En Kant, como se sabe, las preguntas epistemológicas esenciales tienen que ver con las condiciones, los límites y las posibilidades del conocimiento humano. Pues bien, mutatis mutandis, una epistemologia de las ciencias sociales tiene que preguntarse acerca de las condiciones, los límites y las posibilidades del saber sociológico. En Max Weber 
la condición básica para construir conocimiento clentiflco social pasa por la concepluación de la acción racional individual, es decir, por la asumpción de un punto de partida "individualista metodológico"; los limites que encuentra el conocimiento sociológico vienen dados por los procesos de racionalización que ocupan al científico social, es decir, no se puede ir más allá de estos procesos si se quiere estar en el terreno de lo cientificamente fundado; y las posibilidades de este conocimiento no van más allá de lograr una comprensión de los procesos de racionalización particulares y no del conjumlo de los mismos.

\subsection{Supuestos ontológlcos y eplstemológlcos del "Indlviduallsmo metodológlco" contemporáneo}

El "individualismo metodológico" contemporáneo se remonta a Max Weber. En esle senlido, asumen las premisas epistemológicas y ontologicas del planteamiento weberiano. Sin embargo, van más lejos que Weber en lo que loca a la imposibilidad de acceder a la realidad social como tolalidad, asi como también en lo que concierne a la naturaleza de la sociedad. Porque ciertamente en Weber está presente - cmo ya lo senalamos- un cierto "optimismo epistemológico" en lo que se refiere a las posibilidades humanas de conocer globalmente la realidad social. En los pensadores del "nuevo individualismo melodológico" esa posibilidad eslá a priori descartada. Incluso no es exagerado decir que muchos de estos autores asumen en forma militanle una actilud antisistémica, to cual los conduce evidenlemente a enfrentarse con los que de una u otra forma defienden posturas holísticas.

Desde el "individualismo melodológico" conlemporáneo no es posible imaginar un saber cientílico social -que quiera poseer efectivamente ese estaluto- capaz de acceder a la unidad del todo social, porque tal lodo social no existe. Las condiciones básicas del saber sociológico vienen dadas - como en Weber- por la reducción de los procesos sociales complejos en términos de acciones-elecciones racionales de los individuos (J. Elster). Los limites de este saber vienen dados, asimismo, por la complejidad que puedan alcanzar esas acciones-elecciones racionales y por la capacidad que puedan tener los modelos analíticos para dar cuenta de aquella complejidad. Es decir, más allá de las acciones-elecciones racionales individuales (o de los complejos de acciones-elecciones racionales) no se puede ir, al menos desde un punto de visla cientílico-social. Las posibilidades del conocimiento sociológico se restringen, en consecuencia, a desentranar analíticamenle los complejos de la relaciones que los individuos traban entre sí. Por tanto, sólo es posible obtener un conocimiento sociológico efectivo (cientificamente hablando) si se asumen consecuentemente criterios reduccionislas, mismos que 
obligan a una explicación de lo complejo en términos de lo más simple (J. Elster). La posibilidad de acceder al todo social como algo más que la sumatoria de los individuos es algo que queda fuera del horizonte teórico del individualismo metodológico contemporáneo.

En esta tradición teórica nos encontramos con una sustantivación del individuo. Por consiguiente, en el nuevo individualismo melodológico la noción de acción individual no hace referencia, como en Weber, a un medio heurístico o a un instrumento analílico, sino que apunla hacia la constitución misma de lo social. No hay sistema social porque lo social no es más que la sumaloria de los individuos que actuan y eligen en función de sus preferencias personales. Es decir, lo social no es más que la "extensión de las elecciones individuales" (J. Elster). Por tanto, lo único real y sustantivo en el contexto de lo humano-social son las acciones de los individuos. El todo social no se puede sustantivizar porque en cuanto tal carece de realidad; to único real son los individuos y sus elecciones racionales. El "relorno del sujeto" (Pizzorno) significa en esla tradición la "desustantivación de lo social".

$\mathrm{Y}$ juslamente porque lo sustantivo son las acciones individuales es que el nuevo individualismo melodológico puede afirmar que "todas las instiluciones, paulas de comporlamienlo y procesos sociales pueden ser explicados en lérminos de individuos únicamente" (J. Elster). Asimismo, esta suslantivación del individuo (con sus acciones y elecciones) es 10 que pone límites a cualquier prelensión epistemológica lotalizante: no se puede alcanzar una comprensión global de la sociedad porque ésla es inexislente como lotalidad. Lo único existente son los individuos como "álomos" o "mónadas" que ejecutan aquellas acciones que "mejor se ajuslan a sus propósilos" (J. Elster). La sumatoria de las acciones y elecciones de los individuos monádicos constituyen las elecciones y acciones de ese actor supraindividual que es la sociedad. Es asi como generalizando de los individuos a los grupos que se puede alcanzar la comprensión de las elecciones colectivas (R. Benjamin).

Una última reflexión que nos interesa apunlar se sale de lo estrictamente epistemológico y de lo estrictamente ontológico y nos remile hacia las implicaciones políticas del "individualismo melodológico" contemporáneo. No es nada casual que sus portavoces y eplgonos más reconocidos estén vinculados a la olensiva económica y politica de corte neoliberal que el sistema capitalista ha lanzado por el mundo tras el dernumbe del Esle y la desaparición de la URSS. Polílicamente, el "individualismo metodológico" contemporáneo guarda muchas alinidades con el neconservadurismo, lo que significa un alineamiento con una estralegia de lucha contra todo lo que tenga connolaciones de revolución o socia- 
lismo, llámesele Estado benefactor, Nuevos Movimientos Sociales o Teologla de la Liberación. La funciones de legitimación de los programas neoliberales que se implementan en América Latina tampoco son ajenas a los leoricos de la rational choice.

Para ponerlo en términos clásicos - términos que a muchos les molesta hasta escuchar- el individualismo metodologico es más propenso que otras posturas a tomar posiciones de derecha -más que de izquierda- en el espectro político ${ }^{2}$. Muchos dirán que a estas alturas de la historia eso ya no importa, y que lo único importante -dada la ausencia de una altemativa eficaz o viable al proyecto neoliberal- es el avance analítico en la comprensión de los fenómenos sociales. Nosotros prefeririamos guardar una reserva crilica respecto a la idea de que el compromiso político hacia la derecha de los portavoces del "individualismo melodológico" carece de importancia en la actualidad. Desde América Central, donde los efectos del neoliberalismo tienden a ser desastrosos para la mayor parte de la población y la polarización política derecha (=conservadurismo-neoliberalismo)-izquierda (=socialismo-democracia) no es cosa del pasado, las implicaciones políticas del pensamiento social no carecen de imporlancia.

\section{A modo de conclusión}

4.1. Hemos reflexionado en torno a los supueslos ontológicos y epistemológicos que se derivan de la perspectiva melodológica presente en el "individualismo melodológico". Por contraposición a las posturas sistémicas -que hacen del todo social to suslantivo y que, además, alirman la posibilidad de alcanzar una comprensión global de ese todo social-, en el individualismo melodológico hay una suslantivación del individuo (de la acción individual), asi como la afirmación de la imposibilidad de alcanzar una comprensión del todo social en cuanto tal, ya que el mismo es inexistente.

4.2. Por lo demás, es evidente que no puede asumirse una determinada perspecliva metodologica en Ciencias Sociales sin hacerse cargo de los supuestos epistemológicos y ontológicos en que se lundamenta aquélla. En el caso del individualismo melodológico, eslos supueslos apuntan hacia una ontologización de las acciones individuales $y$, en consecuencia, hacia el rechazo de las visiones sislémicas de la realidad social. En el caso de las tradiciones sistémicas, nos las habemos con planleamienlos que ontológicamente privilegian el todo social y que epistemológicamenle sostienen que si es posible lograr una comprensión del mismo.

4.3. Optar por una u otra de las perspeclivas liene consecuencias no 
sólo en orden al conocimiento que se pueda lograr sobre lo humano-social, sino que dicha opción tiene consecuencias que exceden el ámbito académico y que tienen que ver con las implicaciones políticas del saber sociológico. Cuando se hace una opción metodológica no sólo se asumen los supueslos onlológicos y epistemológicos en que se funda dicha orientación melodológica, sino que se asume la orientación ético-política a la que una determinada perspectiva metodológica (con sus supueslos ontológicos y epistemológicos) no sólo da lugar como resultado tinal, sino por la que previamente se ha optado implicila o explicitamente.

\section{México DF, mayo de 1993}

\section{NOTAS BIBLIOGRAFICAS}

1. Aguilar Villanueva, L. F., "El 'individualismo metodológico' de Max Weber". Revista Mexicana de Ciencias Polfticas, 127, p. 151

2. Clr. Otto Apel, K., La transformación de la filosofla Madrid, Taurus, 1983. pp. 75-100. Vol. I

3. Cfr. Elster, J., El cemento de la sociedad. Las paradojas del orden social. Barcelona. Gedisa, 1990; Buchanan, J., Ensayos sobre economia polltica. México, Alianza Editorial Mexicana, 1990; Taylor, M., "Racionalidad y acción colectiva". Zona Abierta 54-55 (1990): 69-114; Olson, M., The logic of collective action. Cambridge, Mass.: Harvard Universily Press, 1965; Banjamin, R., Los limites de la polftica. México. Alianza Editorial Mexicana, 1991

4. Weber, M., Economía y sociedad. México, FCE, 1964. p. 5

5. Weber, M., Ensayos sobre metodología sociológica Buenos Aires, Amorrorlu, 1978. p. 187

6. Aguilar Villanueva, L. F., Ob. Cit. p. 163

7. Ib. p. 159

8. Ib. p. 158

9. Aguilar Villanueva, L. F., "En torno al concepto de racionalidad en Max Weber". En Olivé, L. (Compilador), Racionalidad. Ensayos sobre la racionalidad en ética y polftica, ciencia y tecnologla. México. Siglo XXI, 1988. p. 88

10. lb. p. 78

11. Ib., Nota 1

12. Ib. p. 159

13. Ib.

14. Ib.

15. Przeworski, A., "Marxismo y elección racional". Zona abienta 45(1987): 97

16. Cfr. Schumpeler, J., Capitalismo, socialismo y democracia. Barcelona, Orbis, 1983. 2 Vol.

17. Buchanan, J., Ib., p. 28 
18. Elster, J., "La posibilidad de una polílica racional". En Olivé, L. (Compilador), Ob. Cit., pp. 132 y ss.

19. "Presentación". Zona abierta 54-55(1990):1

20. Benjamin, R., lb., p. 20

21. Ib., Nota 19

22. Ib. p. 2

23. Colom González, F. Las caras de Leviatán. Una lectura politica de la teoría critica. Barcelona, Anthropos, 1992. p. 59

24. Un pionero en estos estudios ha sido sin duda Mancur Olson, cuya obra principal lleva por titulo The logic of collective action. Cambridge, Mass.: Harvard University Press, 1965. Para un sumario de las tesis de Olson. Cfr. Aguilar, F., "Lógica de cooperación". Zona Abierta 54-55 (1990): 10 y ss.

25. Una muestra bastante representativa de las preocupaciones que ocupan la atención del "nuevo individualismo metodológico" se encuentra en el número 54-55 de la revista Zona Abierta (1990).

26. "Presentación". Zona Abierta... p. 3. Cir. Aguilar, F., "Lógica de cooperación". Zona Abierta 54-55 (1990): 15 y ss.

27. Elster, J., Una introducción a Karl Marx. México, Siglo XXI, 1992. p. 28-29

28. Elster, J., Ob. Cit. p. 24

29. Clr. Luhmann, N., Sistemas sociales. Lineamientos para una teoria general. México, Universidad Iberoamericana-Alianza Editorial, 1991

30. Clr. Althusser, L., "Ideologla y aparatos ideológicos de Estado (Notas para una investigación)". En La filosolla como arma de la revolución. México, Siglo XXI, 1974. pp. 102-151

31. Izuzquiza, I., La sociedad sin hombres. Niklas Luhmann o la teorla como escándalo. Barcelona, Anthropos, 1990. p. 11

32. Aunque esto evidentemente tiene que ser matizado. Porque pensamientos sistémicos pueden asumir $-y$ a lo largo de la historia del pensamiento social han asumido muchos de ellos- posiciones de derecha. El ejemplo más reciente es la teorla de sistema de Luhmann que a juicio de Habermas está comprometida con posturas conservadoras. Cfr. Habermas. J., Teoría de la acción comunicativa Madrid, Taurus, 1989. Vol. II 